\title{
Strategic analysis on the integration of agricultural holding assets
}

\author{
Ekaterina Ogorodnikova*, Maria Khokholush, and Konstantin Rostovtsev \\ Ural State University of Economics, 620144, 8 Marta Str, 62, Ekaterinburg, Russia
}

\begin{abstract}
The topic of integration of agricultural and food enterprises into holdings, the strategy of their cooperation and integration is of great importance for the food security of the country. The article presents the results of a study of the integration of the agricultural holding Rusagro, based on the use of a matrix of dependence of the company's profitability indicators on its relative value in the market. Approbation of this method allows to reasonably make management decisions regarding the development of an agricultural holding.
\end{abstract}

\section{Introduction}

Agriculture is the most subsidized area of doing business in the Russian Federation, and the state emphasizes the strategic importance of supporting this industry to achieve food security and social stability of the state [1]. At the same time, large agricultural producers are trying to find mechanisms to independently increase the stability and profitability of their business. One of these mechanisms is the process of integration and association. Agricultural markets and food markets are volatile. The state of demand for products is influenced by such factors as yield, market saturation, the ability to carry out export deliveries and government policy in relation to the import of products. The indicated influences create significant risks for the enterprises of the agro-industrial holding, which in turn causes the desire of agricultural holdings to minimize risks by diversifying business and compensating for losses in one area of activity due to successes in another $[2,3]$. The question arises, what structure of the holding should be chosen, what types of activities and enterprises should be included in the holding and how to bring the organization to the necessary criteria for strengthening its position in the market and increasing financial performance. The topic of combining enterprises into holdings, the strategy of their cooperation and integration is of great importance for agricultural holdings, certain aspects of this issue were considered in works [4] and [5]. The topic of institutional influence on the integration processes of agricultural producers and the formation of synergistic effects in the course of such integration is also widely discussed $[6,7]$.

\footnotetext{
* Corresponding author: cmb_8@mail.ru
} 


\section{Materials and Methods}

As a research method, a matrix of dependence of the company's profitability indicators on its relative value in the market is used. The value of the company's assets located on the abscissa (X-axis) reflects the desire to increase its presence in the market, due to the growth of profitability in a particular business division. On the ordinate (Y-axis) value of profit indicates the level of profitability of a particular business division [8].

Interpretation of business strategies using a matrix of dependence of the company's profitability indicators on its relative value in the market involves the allocation of three zones. The first of them is the zone of increased profitability of the agricultural holding, which signals the preference for the strategy of increasing the size of the company. The second zone - a stable level of the company's profitability indicates the absence of a threat of a reduction in the size of the company's assets and the absence of prerequisites for an increase in the size of the company. The red zone indicates a low level of profitability and the threat of a decrease in the presence on the presented market. Possible strategies fit into three directions, each of which has specific solutions.

The first is a growth strategy by activating business divisions that show the highest profitability. The main efforts in the implementation of this strategy are aimed at promoting the existing product on the market.

Second, the asset optimization strategy is used to consolidate resources in order to expand to promising market segments. The main solution is to retain the most profitable assets that generate the bulk of the profit and remove the less profitable business units from the portfolio. The result is an avalanche-like dynamics of an increase in the profitability of individual business units with a general decrease in their number.

The third is the strategy of reducing the size of the company, in which a systematic decrease in the value of assets is carried out in proportion to the decrease in profits. The strategy can be used by an agricultural holding if it is necessary to reduce one of the business divisions in order to obtain funds to strengthen another more promising direction. The strategy of reducing the size of the company is characterized by the fact that the most liquid assets are subject to sale, but the condition of ensuring an acceptable level of profit during the liquidation of the business remains.

\section{Results and Discussion}

As an indicator of the size of the company, the characteristic of the size of the company's non-current assets is used. The gradation is made in three levels: low, medium, high. The maximum value of the characteristic of non-current assets is taken to be the largest value of assets, relative to this value, the values of the characteristics are determined: high - at least $70 \%$ of the maximum value of the characteristic; medium - in the range of $30 \%-70 \%$ of the maximum value of the characteristic; low - less than $30 \%$ of the maximum value of the characteristic.

As an indicator of the company's profit, the characteristic of the profitability of the company's non-current assets is used. The gradation is made in three levels: low, medium, high. High profitability is considered to be over $25 \%$; medium - in the range of $5 \%-25 \%$; low - less than $5 \%$. Next, we present information for compiling a matrix, table 1 . 
Table 1. Initial data for compiling a matrix of dependence of the company's profitability indicators on its relative market value for the Rusagro agricultural holding, 2013-2017

\begin{tabular}{|c|c|c|c|c|c|c|c|c|}
\hline \multirow[b]{2}{*}{ Holding business unit } & \multicolumn{2}{|c|}{2014} & \multicolumn{2}{|c|}{2015} & \multicolumn{2}{|c|}{2016} & \multicolumn{2}{|c|}{2017} \\
\hline & 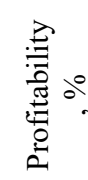 & 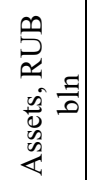 & 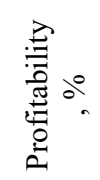 & 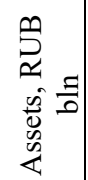 & 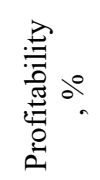 & 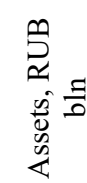 & 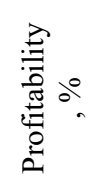 & 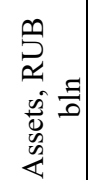 \\
\hline Fat a & 14,46 & 17,3 & 14,46 & 17,3 & 4,35 & 19,9 & 4,35 & 4,55 \\
\hline Agric & 2,07 & 10,7 & 2,07 & 10,7 & 2,56 & 20,21 & 2,27 & 18,8 \\
\hline Meat processing & 4,52 & 18,1 & 4,52 & 18,1 & 3,97 & 17,9 & 6,02 & 20,5 \\
\hline Sugar production & 14,49 & 22,5 & 14,49 & 22,5 & 13,86 & 37,2 & 12,19 & 30,4 \\
\hline
\end{tabular}

Next, we present the matrix for the portfolio of business units of the Rusagro agricultural holding, Figure 1.

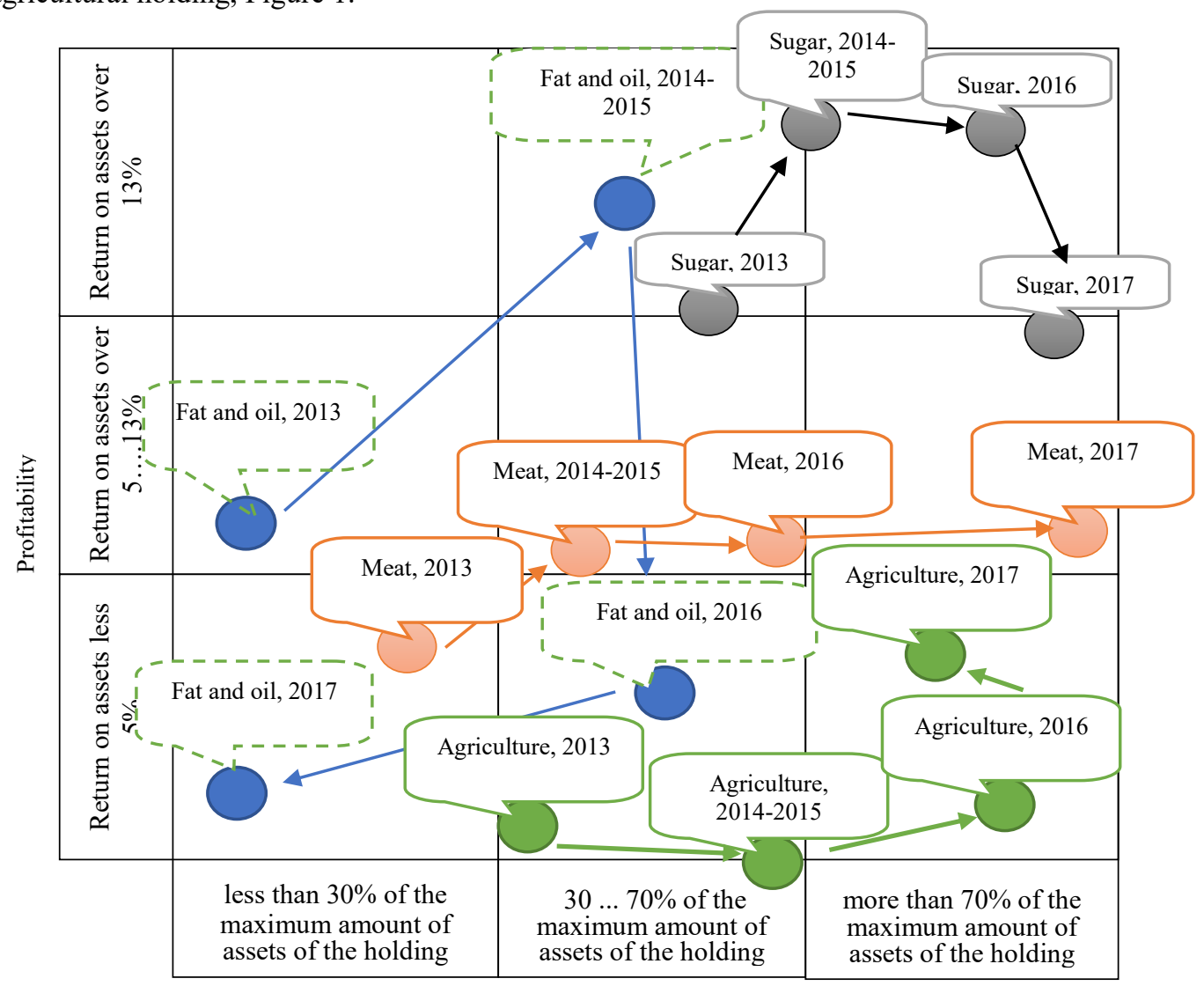

Assets

Fig. 1. Matrix of the relationship between company size indicators and its profit for 2013-2017.

The analysis allows us to conclude that 2017 was characterized by a dramatic decline in indicators in all business areas, except for the fat and oil segment. In the fat-and-oil 
segment, management errors were identified and eliminated, while simultaneously with the acquisition of assets and the adjustment of the strategy towards increasing the profitability of assets, the segment was successfully brought to the zone of high sustainable profitability indicators. In the meat segment, the downward trend in profitability, noted in 2016, continued to develop and, simultaneously with the acquisition of additional assets, brought the business into a zone of ineffective return on assets. According to the company's comments, the situation is not critical and despite the decline in the profitability of noncurrent assets, EBITDA showed growth due to an increase in the volume of these assets. In the current situation, according to the methodology of the applied analysis matrix, the company has two development alternatives: increasing the profitability of assets or removing them from the portfolio of business areas. In the sugar segment, the reason for the collapse in profitability is the pressure on prices, supported by the low world price, which led to a fall in the market in monetary terms. In 2017, sales prices for the company's sugar products fell by $23 \%$ to RUB 30.6 per kilogram excluding VAT. As a result, the profitability of the business has decreased. In the agricultural segment, there was also a landslide drop in prices for manufactured products due to record agricultural production in Russia and around the world. In addition to this, costs increased, in particular for fuel and lubricants, wages and land rent. The current state of affairs requires adjusting the company's strategy.

As a result of the study, the following main directions for the implementation of the agricultural holding's strategy can be identified:

In the segment of sugar production:

- increasing the productivity of factories in the Kursk region up to 5.0 thousand tons per day;

- reconstruction of the Krivets-Sugar plant;

- commissioning of a sugar silo with a capacity of 60 thousand tons.

In the segment of meat processing:

- increase in production up to 204 thousand tons of pork in live weight;

- management, control and reduction of production costs.

In the segment of agricultural production:

- an increase in the land bank by 20 thousand hectares: in the Tambov region - by 10 thousand hectares, in the Primorsky Territory - by 10 thousand hectares;

- technical re-equipment of the existing fleet of equipment, as well as providing new lands with equipment;

- business automation and launch of a breeding center for the development of improved sugar beet hybrids.

In the fat and oil segment:

- modernization of the existing production site of the oil extraction plant;

- construction of a site for obtaining lecithin;

- construction of a warehouse for finished products, designed to store the weekly production volume.

Thus, the use of matrix analysis tools in the long term will allow the agricultural holding to reach an acceptable level of profitability and will exclude from the development process a significant dependence on financing in the form of government support.

\section{Conclusion}

The strategic analysis tool presented in the article is used for the process of merging and developing enterprises, including agricultural holdings. The matrix of dependence of the company's profitability indicators on its relative value in the market allows to assess the risks that an enterprise may face without applying the correct strategy. The ways and 
methods of choosing the direction of development are considered. The analysis of the enterprise strategy is presented on the example of the agro-industrial holding "Rusagro" Group of Companies. The obtained research result is expressed in the form of a conceptual vision of the agricultural holding's strategy for future periods. The relationship between the value of non-current assets and the levels of profitability has been revealed. The investigated approaches make it possible to predict the market situation, analyze its processes and develop measures for the company's timely response to external changes. The results obtained in the work will allow developing the methodological aspects of the formation of holding strategies. The process of integration and merger of enterprises plays an important role for the country as a whole and can become an instrument for ensuring food security of the state, improving the situation of Russian enterprises, strengthening the country's economy as a whole.

\section{References}

1. V. Uzun, N. Shagaida, Z. Lerman, Land use policy, 83 (2019)

2. O. Kozlova, E. Lubkova, A. Shilova. IOP Conference Series: Earth and Environmental Science. 459, 6 (2020)

3. R. E. Hoskisson, T. A. Turk, Academy of management Review, 15, 3 (1990)

4. M.Graubner, I. Ostapchuk, T. Gagalyuk. European Review of Agricultural Economics, 48,1 (2021)

5. O.Skydan, O. Budnik, L. Sus. Agricultural and Resource Economics: International Scientific E-Journal, 7 (2021)

6. A. Plakhin, E.Ogorodnikova, M. Khokholush, T.Guseva, M. Selezneva, Revista Inclusiones, 20 (2020)

7. A.Plakhin, E. Ogorodnikova, T. Kochergina, T. Guseva, M. Selezneva Amazonia Investiga, 9, 26 (2020)

8. N. Morozko, N. Morozko, V. Didenko Journal of Reviews on Global Economics, 7 (2018) 